
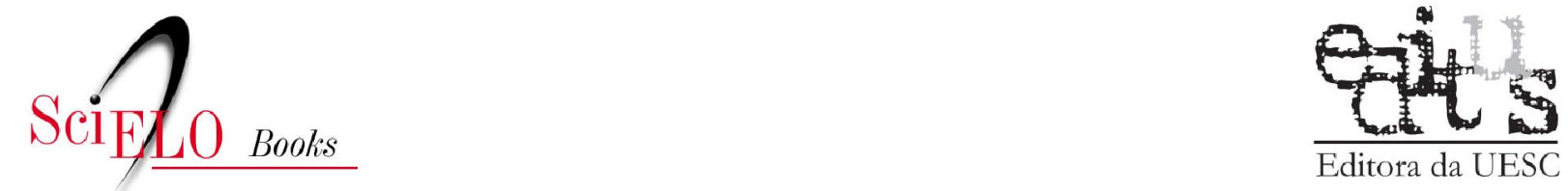

\title{
12 Produção de sementes e mudas florestais
}

\author{
Danilo Sette de Almeida
}

SciELO Books / SciELO Livros / SciELO Libros

ALMEIDA, DS. Produção de sementes e mudas florestais. In: Recuperação ambiental da Mata Atlântica [online].3rd ed. rev. and enl. Ilhéus, BA: Editus, 2016, pp. 170-182. ISBN 978-85-7455440-2. Available from SciELO Books $<\underline{\text { http://books.scielo.org }>\text {. }}$

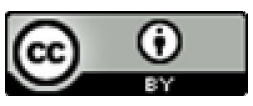

All the contents of this work, except where otherwise noted, is licensed under a Creative Commons Attribution $\underline{4.0 \text { International license. }}$

Todo o conteúdo deste trabalho, exceto quando houver ressalva, é publicado sob a licença Creative Commons Atribição 4.0.

Todo el contenido de esta obra, excepto donde se indique lo contrario, está bajo licencia de la licencia $\underline{\text { Creative }}$ Commons Reconocimento 4.0. 


\section{2}

\section{PRODUÇÃO DE SEMENTES E MUDAS FLORESTAIS}




\subsection{Suprimento de sementes}

opção por modelos de recuperação, que necessitam de se-
mentes para uso direto ou produção de mudas, pode ser um
grande problema para a região da floresta atlântica. Assim, em função da escala do projeto a ser executado, da área a ser recuperada, do tempo de execução do serviço e da existência de matrizes das espécies selecionadas, deve ser analisada a melhor alternativa para o suprimento de sementes: compra ou coleta própria na região de implantação do projeto.

Quando pensamos em compra de sementes, existem vários bancos de sementes, fornecedores de propágulos de floresta atlântica no Brasil, a maioria deles ligada a institutos de pesquisas e Universidades, e a algumas ONG's. As sementes, fornecidas por estes bancos, são geralmente acompanhadas de informações como percentagem de germinação, sistema de quebra de dormência e número de sementes por quilo, facilitando o planejamento da compra e da produção de mudas. As sementes provenientes destes bancos possuem como vantagem a garantia de qualidade. Entretanto, em função da própria demanda atual e da variabilidade da composição florística da floresta atlântica, nas diferentes regiões, a maioria das instituições não apresenta uma variedade de espécies suficientes para atender às necessidades de programas regionais de recuperação, que tenham como objetivo a recomposição da biodiversidade, específica para determinadas regiões. Observa-se também que muitos estados da costa atlântica não possuem sequer um banco de sementes.

Uma segunda alternativa é implantar um sistema próprio de coleta de sementes, tendo de formar uma equipe própria, ou terceirizada, de coletores. Neste caso, é importante primeiramente definirmos com quais espécies vamos trabalhar. Esta seleção é feita, como vimos, com base nos levantamentos florísticos e fitossociológicos e observações de campo, nos diversos estágios sucessionais da floresta, que queremos recuperar. Definidas as espécies, é necessário obtermos uma série de informações, como: existência de matrizes na região, época de frutificação, número de sementes por quilo, existência de dormência, melhor embalagem e condições para armazenamento. O conhecimento da fenologia das espécies (época de floração, frutificação e outras modificações) pode ser realizado em 
fichas apropriadas pela própria equipe de coleta de sementes. Geralmente, as informações citadas em literatura não vão ser exatas para sua região de trabalho, mas poderão nortear os primeiros passos, que se ajustam ao andamento dos trabalhos de fenologia. Devemos selecionar no mínimo dez matrizes de cada espécie selecionada (se possível mais), para a coleta de sementes, buscando uma variabilidade genética da espécie selecionada. Este número mínimo pode ser ampliado, em função da disponibilidade de matrizes. As matrizes são escolhidas, baseadas em características fenotípicas, ótimas para acelerar o processo de recuperação, devemos dar preferência à coleta de sementes na região onde estaremos fazendo a recuperação ambiental. De posse de todas estas informações, é possível planejar a coleta periódica (mensal, por exemplo), especificando qual espécie e qual quantidade de sementes a ser coletada pela equipe, de maneira a atender à necessidade de produção de mudas de seu programa. Este planejamento vai racionalizar os custos operacionais de coleta de sementes.

É importante, do mesmo modo, um bom treinamento da equipe de coleta de sementes, existe uma péssima tendência das pessoas coletarem sementes de árvores com características não desejáveis, pois são, geralmente, as de mais fácil acesso (porte baixo, galhos caídos). Desta maneira, estaríamos realizando um "pioramento" genético. Portanto é necessário especificar as características desejáveis para as árvores matrizes e ter uma participação de um técnico capacitado em sua seleção e marcação.

\subsection{Produção de mudas}

Considerando a diversidade florística e de ambientes presentes na floresta atlântica, um viveiro de mudas deve ser planejado, desde seu início, para produzir plântulas adaptadas às diferentes condições de campo encontradas. Em uma área de produção de mudas de floresta atlântica, devemos planejar o uso dos espaços conforme a demanda de mudas para o programa de recuperação. Normalmente, um viveiro deve possuir uma área de sombra (para produção de mudas para utilização em plantios de enriquecimento e para determinadas espécies que exigem esta condição na fase inicial), e uma grande área aberta exposta à luz solar direta, para produção de mudas aclimatadas para sobreviver nestas condições. 


\subsubsection{Escolha da área}

Para escolha de uma área de produção de mudas, temos de atender a algumas exigências básicas:

a) Água - em quantidade e qualidade suficiente para atender sua produção. Se utilizarmos água de cursos de água próximos, devemos saber se são perenes, se a vazão atende à demanda do futuro viveiro, além de conhecer a qualidade da água.

b) Acesso - deve ser de fácil acesso para facilitar o transporte das mudas para o campo, também deve ficar o mais próximo possível do local de plantio.

c) Topografia - não devemos escolher área que necessite de grandes obras de terraplanagem, a declividade deve variar entre $3-5 \%$. Devem ser evitados locais sujeitos à inundação, como margens de rios que transbordam anualmente.

d) Mão de obra - deve ser encontrada disponível nas proximidades da área do viveiro, reduzindo custos de transporte.

Um grande erro cometido por viveiristas é a produção de mudas em áreas extremamente sombreadas. As mudas produzidas, nestas condições, apresentam-se tenras e bonitas, porém, quando levadas para a área de plantio, têm grande mortalidade, pois não estavam ambientadas com a insolação direta e as altas temperaturas.

\subsubsection{Zoneamento}

Em um viveiro de nativas, devemos planejar os espaços, conforme demanda de mudas para o(s) programa(s) de recuperação que se pretende atender. Em áreas de floresta atlântica, na qual possuímos uma grande diversidade de condições ecológicas e de espécies, é interessante que, no viveiro, principalmente se for um viveiro permanente, tenha diferentes "ambientes" destinados à produção de mudas de diferentes condições ecológicas.

Existem basicamente dois tipos de viveiros - os permanentes e os temporários. Os permanentes são aqueles projetados para 
atender a programas de recuperação em grande escala, visto que é necessária a produção contínua de mudas por um longo período. Nestes casos, vale a pena aplicar maiores investimentos, incluindo uma área de sombra (recomenda-se o sombrite 50\%), área de produção de mudas com tubetes, além de galpão e depósitos para terra e compostos orgânicos. Já, em viveiros temporários, com duração prevista entre 1-2 anos, utilizamos em geral embalagens plásticas, e suas áreas de sombra são construídas com material da região (folhas de palmeiras, por exemplo).

Com referência à quantidade de mudas a serem produzidas, nesta fase, como em todo o processo de recuperação ambiental de áreas degradadas, devemos racionalizar e reduzir custos. Em função da área a ser recuperada, é preciso considerar o número de mudas necessário a ser produzido, computando percentuais de perda no viveiro e no campo (necessidade de replantio).

Normalmente, devemos possuir, em um viveiro de produção de mudas, as seguintes áreas:

a) Sementeiras - áreas onde são semeadas, principalmente propágulos de espécies que demoram em germinar. Atualmente existe uma grande tendência à realização do semeio direto, porque os custos de repicagem são eliminados, reduzindo o valor final da muda. As sementeiras devem ser utilizadas para sementes que demoram a germinar, como as de algumas palmeiras.

b) Área de repicagem - área de permanência temporária de mudas, com sombra de $50 \%$ ou mais, onde a plântula passa pela fase de pós-repicagem (passagem da sementeira para a embalagem plástica ou tubete). Nesta área de sombreamento mais forte, as mudas passam normalmente 1-2 semanas, conforme a espécie. Em viveiros temporários, pode ser utilizada a sombra de árvores bem densas para servir como área de pós-repicagem das mudas recém-repicadas.

c) Galpão - estrutura utilizada para depósito de terra e demais componentes dos substratos utilizados que não podem ser molhados para não atrapalhar as atividades de rotina do viveiro de produção de mudas. Em dias de chuva, os trabalhos - enchimento de embalagens - podem se concentrar nesta área. É interessante que seja anexado, a esta área, o almoxarifado. 
d) Depósitos - normalmente, temos depósitos separados para ferramentas (áreas de uso menos restrito, local em que os funcionários do viveiro têm acesso aos EPIs e ferramentas necessárias para o trabalho do dia a dia), adubos (utilizados quando necessário, é uma área que somente o encarregado do viveiro tem acesso e autoriza retirada) e, quando for o caso, as áreas de depósitos especiais para os agrotóxicos, que por ventura sejam utilizados no viveiro, devem ser armazenadas em lugares individuais e atendendo às condições estabelecidas nas legislações - federal, estadual e municipal -, específicas sobre o assunto.

e) Área de sombra - as áreas de sombra do viveiro estão presentes em qualquer tipo de viveiro de produção de mudas florestais (nativas e exóticas). São as áreas nas quais as mudas passam os primeiros meses de sua vida. Algumas mudas permanecem menos tempo nestas áreas (mudas de espécies pioneiras e secundárias iniciais), e outras podem ficar, nestas áreas, até o momento de plantio no campo, como no caso de mudas de espécies secundárias tardias e clímax, destinadas a plantios de enriquecimento - em ambientes já sombreados. Em viveiros permanentes, recomendamos que esta área seja coberta por sombrite $50 \%$, que atende bem à necessidade lumínica das mudas. Estes sombrites de vários níveis de sombreamento são, facilmente, encontrados no mercado e fornecem um nível de sombreamento uniforme em toda a área da casa de sombra. Eles são de fácil colocação e devem ser bem esticados para homogeneizar dentro da casa de sombra o nível de sombreamento, fornecido para as mudas produzidas. A FOTO 20 mostra uma casa de sombra coberta com sombrite $50 \%$, em que as mudas passam os primeiros meses da fase de produção, neste caso, foi utilizado o sistema de bandejas de chão. No caso de viveiros temporários, a área sombreada pode ser implantada, aproveitando a sombra de árvores já existentes ou coberta por folhas de palmeiras da região, reduzindo o investimento com a construção de uma área de sombra. 
FОTО 20 - Área de sombra, coberta com sombrite $50 \%$, onde as mudas passam os primeiros meses da fase de produção

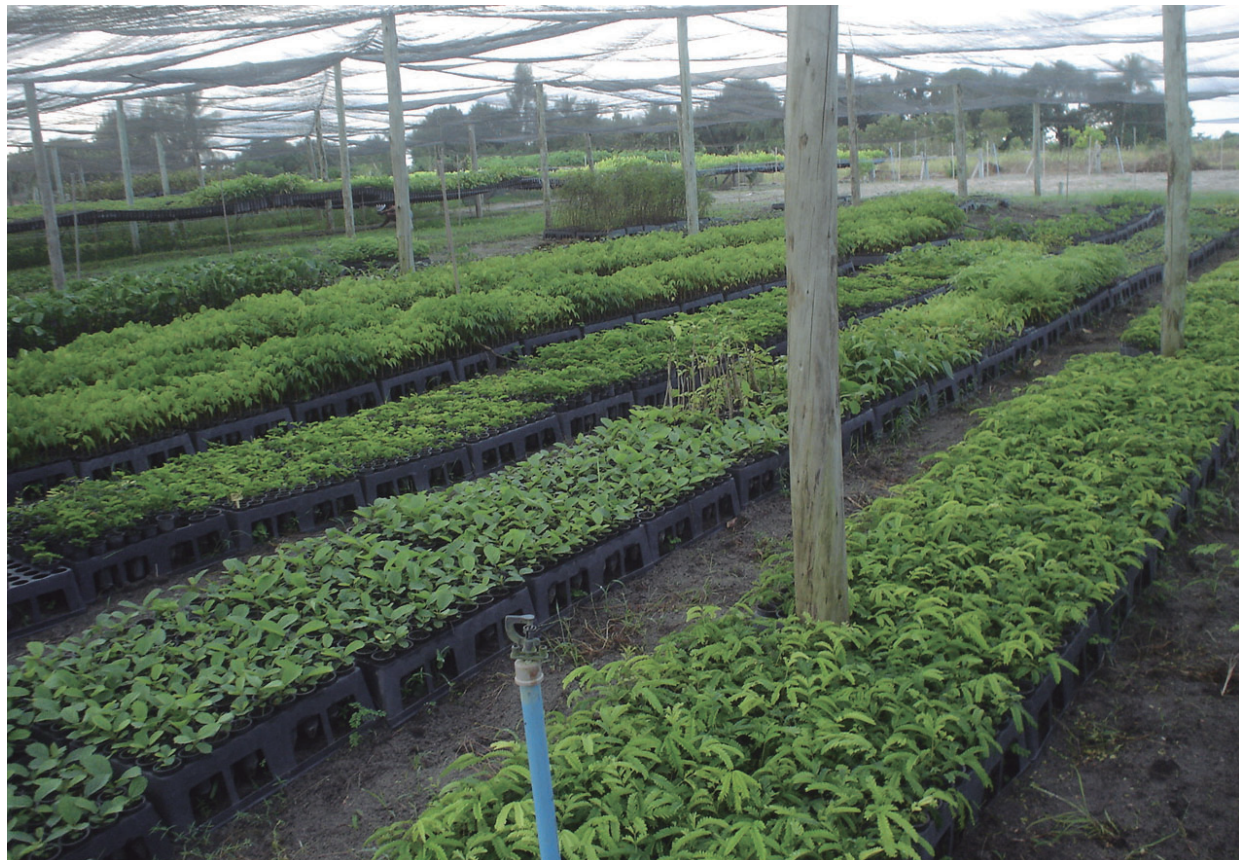

f) Área de rustificação - constitui-se em uma área onde as mudas estão expostas diretamente à luz solar direta, para produção de mudas que vão ser plantadas, nestas mesmas condições no campo. A área de rustificação é a última etapa do processo de produção de mudas florestais nativas. Principalmente, quando falamos de mudas de espécies pioneiras e secundárias iniciais, elas são mudas que, naturalmente, ocorrem em áreas abertas, portanto a área de rustificação se torna muito importante para aclimatação destas mudas.

Na FOTO 21, é mostrada uma área de rustificação, completamente sem sombreamento, onde as mudas recebem diretamente a luz do Sol, condição semelhante a que encontrarão após o plantio no campo. Nestas áreas de rustificação, as mudas sofrem uma redução gradual da irrigação fornecida, também visando maior adaptação às condições que serão encontradas no campo. Estas mudas rustificadas estão prontas para plantio e a resistir às condições que serão encontradas após o plantio.

g) Viveiro de espera - área onde as mudas são plantadas diretamente no solo, sistema muito utilizado para produção de mudas para arborização urbana. Neste local, as mudas podem atingir maior 
FOTO 21 - Aspecto de área de rustificação/aclimatação etapa final da produção de mudas que antecede expedição para plantio

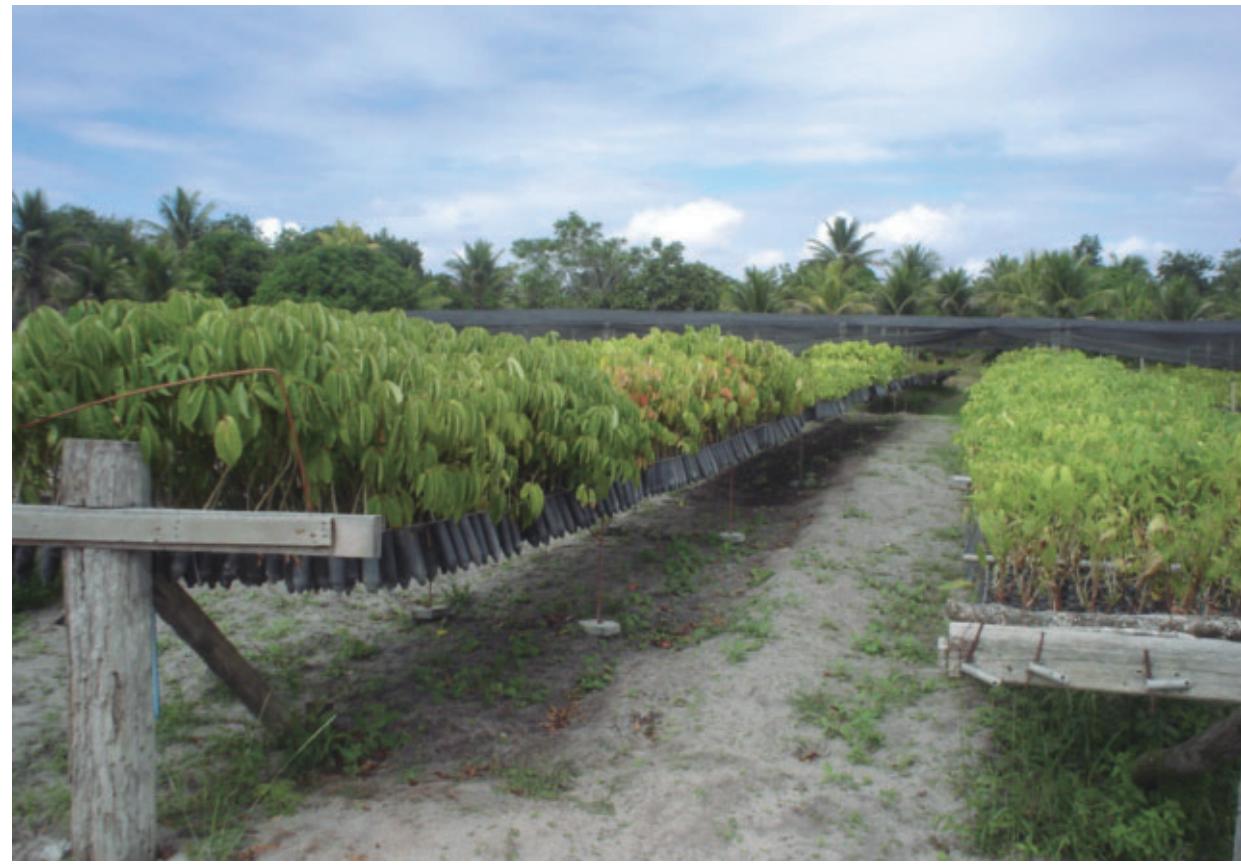

porte. Em alguns casos especiais, estas mudas poderiam atender à demanda para recuperação de áreas degradadas. Considerando o tempo de formação de mudas, cuidados especiais e custo da retirada, o valor final desta muda se torna alto.

\subsubsection{Recipientes para produção de mudas}

Temos hoje uma grande variedade de tipos de recipientes. Os mais utilizados são a tradicional sacola plástica e os tubetes de polietileno. As sacolas plásticas de tamanhos variados são bons recipientes, principalmente para mudas que necessitam de maior tempo para ficarem prontas para expedição. Elas apresentam como principais vantagens o fácil manuseio, a facilidade de encontrar no mercado e custo reduzido (em comparação com outros recipientes). Como desvantagens, citamos o grande risco de enovelamento de raízes, exigindo constante removimento das mudas de local.

Os tubetes - tubos duros de polietileno - são recipientes muito utilizados para produção de mudas florestais em grande escala. Existem, no mercado, tubetes de vários tamanhos, inclusive 
para produção de mudas de grande porte. Eles apresentam como vantagens o menor gasto de substrato (volume) em comparação com as embalagens plásticas, a facilidade de manuseio no viveiro. Os tubetes são recicláveis, não deixam resíduos na área de plantio, devido a seu tamanho reduzem o custo de transporte para a área de implantação e facilitam as operações de plantio. Outra grande vantagem sobre outros sistemas, é que, geralmente, comportam mais mudas por unidade de área de viveiro, necessitando menor área total de viveiro, reduzindo diversos custos como irrigação, substratos, mão de obra. Também é menor o risco de enovelamento de raízes, pois os tubetes possuem estrias que conduzem as raízes para baixo. A principal desvantagem é o investimento inicial, necessário para a adoção destes recipientes - construção de estaleiros (suportes), compra de bandejas e tubetes - o que é compensador apenas para viveiros permanentes (que vão produzir mudas por vários anos consecutivos). No mercado, encontramos tubetes de tamanhos variados (100 cc, $176 \mathrm{cc}, 290 \mathrm{cc}$, etc.) que devem ser adequados para as produções de mudas de variadas espécies nativas. Como regra geral, os tubetes maiores são utilizados para espécies que permanecem mais tempo no viveiro, e os tubetes pequenos, para espécies que ficam menor período na área do viveiro, normalmente espécies pioneiras. Na FOTO 22, podemos observar um tubetão para a produção de mudas nativas.

\subsubsection{Substratos}

Em função do recipiente escolhido, da quantidade e do tipo de muda a ser produzida, do sistema de propagação (sementes ou estacas), devemos definir o substrato que vamos utilizar. Geralmente, mudas florestais necessitam de substratos com um bom teor de matéria orgânica. Um bom composto orgânico (a base de esterco bovino e capim picado, por exemplo) é uma boa opção para compor até $100 \%$ do substrato. Outro componente importante é a terra, necessária para criar uma agregação do substrato, deve ser de textura argilosa e compor de $25 \%$ a $40 \%$ do substrato, este componente é indispensável no caso de embalagens plásticas. É recomendável que a terra utilizada seja proveniente de subsolo, evitando, assim, a presença de sementes de ervas daninhas. $\mathrm{O}$ restante do substrato pode ser preenchido com material orgânico decomposto como pó de 


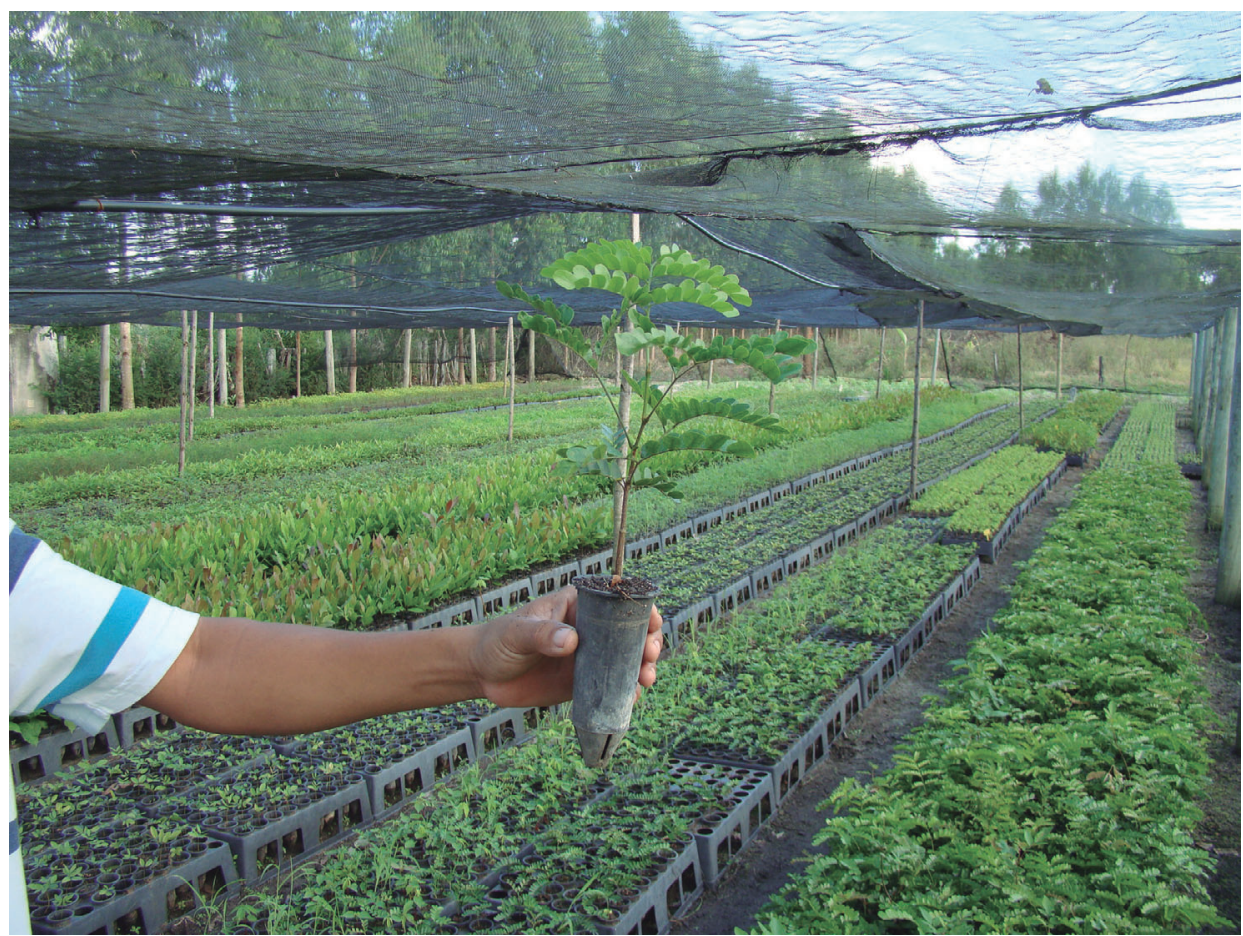

serra, casca de arroz (carbonizada), moinha (pó) de carvão, ou outro produto orgânico ou mineral que seja comum e barato na região do viveiro. Um importante substrato utilizado hoje, no Brasil, principalmente para a produção de mudas de eucalipto, é a vermiculita. Apesar do inconveniente do alto custo, é um substrato leve, livre de pragas e doenças, e retém bem a adubação mineral. Este substrato igualmente pode ser misturado com outros em proporções variadas. Em pequenos viveiros, recomendamos a utilização de compostos orgânicos, que podem ser produzidos na própria área do viveiro, e, considerando custo e benefício, fornecem bons resultados.

\subsubsection{Irrigação}

O sistema de irrigação deve ser planejado conforme tamanho e objetivo do viveiro. Para viveiros temporários, que têm como objetivos atender somente a recomposição de determinada área, em função do tamanho, a irrigação poderá ser realizada com regadores ou mangueiras. Já em viveiros permanentes, recomenda-se a 
implantação de um sistema fixo de irrigação, via aspersão, que vai facilitar e baratear, em longo prazo, esta operação.

As diferentes áreas existentes dentro de uma área de produção de mudas demandam diferentes tipos de aspersores e turno de rega. Normalmente sementeiras, ou áreas com embalagens recémsemeadas, necessitam de aspersão pulverizada (pequenas gotículas) com objetivo de não revolver o substrato que cobre as sementes. Já em áreas onde as mudas são adultas, aspersores grandes, que cobrem maior raio de irrigação podem ser utilizados com maior rendimento. Entretanto, visando facilitar a parte operacional e o planejamento, o ideal é se adotar um sistema único de aspersores. Quanto ao horário da irrigação, em dias ensolarados, o ideal é se aplicar uma irrigação pela manhã (o mais cedo possível) e outra, no final da tarde (quando o sol já está se pondo), evitando ao máximo a irrigação nas horas mais quentes e ensolaradas do dia. Em dias quentes e de grande insolação, recomenda-se 2 a 3 irrigações por dia; já, em dias chuvosos, em função da quantidade de precipitação, esta operação pode ser cancelada.

\subsection{Equipe de implantação e manutenção}

Considerando a especificidade dos serviços referentes à recuperação de áreas degradadas, em função da escala do projeto, é importante a formação de equipe multidisciplinar para elaboração e implantação desta tarefa. Desde a fase de reabilitação da estrutura - tratamentos no meio físico - do sistema, até a reintrodução das espécies vegetais e animais, uma série de profissionais de diversas áreas de conhecimentos são envolvidos. Também na fase de implantação, devido à especificidade das operações, desde o preparo do terreno até o plantio das mudas, para obtermos melhores rendimentos operacionais, é conveniente investirmos na formação de uma equipe especialista nestes serviços. Existem variações regionais nos rendimentos de operações de recuperação - limpeza de área, coveamento, adubação, combate à formiga e plantio - e uma equipe treinada pode reduzir em muito o custo final do projeto. Os serviços de manutenção, básicos para o sucesso do projeto, também devem ser realizados por equipes com experiência. Serviços de limpeza de área (roçadas e capinas) requerem conhecimento dos trabalhadores, que deverão saber identificar as espécies vegetais 
plantadas, além de conhecer a regeneração natural que não deve ser eliminada. Portanto, todos os trabalhadores, desde técnicos até operários, devem ser capacitados para desenvolver a contento seu papel.

Por se tratar de um projeto com muitas especificações desde coveamento, espaçamento até distribuição das espécies na área, é necessário o acompanhamento de um técnico capacitado durante todas as etapas de serviços de implantação e manutenção. No caso da existência de equipe de campo treinada, neste tipo de serviço, são necessárias apenas supervisões técnicas periódicas, variando conforme escala do projeto.

\subsection{Aspectos legais relacionados às mudas e sementes Florestais}

Para desenvolvimento de atividades, na área de coleta de sementes e produção de mudas florestais, existem procedimentos legais que devem ser seguidos. A lei básica que trata sobre este assunto é a Lei n. 10.711, de 05 de agosto de 2003, que dispõe sobre o Sistema Nacional de Sementes e Mudas e dá outras providências. Através desta lei, fica instituído, no Mapa, o Registro Nacional de Sementes e Mudas - RENASEM. Esta lei criou o Sistema Nacional de Sementes e Mudas, que tem como objetivo garantir a identidade e a qualidade do material de multiplicação e de reprodução vegetal produzido, comercializado e utilizado em todo o território nacional. Assim, todo produtor de sementes e mudas tem de possuir seu RENASEM.

Através da Instrução Normativa n. 24/2005, o Ministério da Agricultura e Pecuária (MAPA) fixa as diretrizes básicas a serem obedecidas na produção, comercialização e utilização de mudas, em todo o território nacional, visando à garantia de sua identidade $\mathrm{e}$ qualidade.

Especificamente para Produção, Comercialização e Utilização de Sementes e Mudas de Espécies Florestais, Nativas e Exóticas, temos a Instrução Normativa n. 56, de dezembro de 2011, que determina as normas para o produtor de sementes e mudas de espécies florestais. Hoje, além do registro obrigatório, existe a necessidade de termos um responsável técnico pela atividade (também inscrito no RENASEM), Engenheiro Florestal ou Engenheiro Agrônomo, com 
seu respectivo registro no CREA e Anotação de Responsabilidade Técnica (ART). Existem várias normas a serem seguidas e também a necessidade de apresentação de uma declaração anual da fonte de sementes de cada espécie, que pretenda produzir, assim como a produção estimada de mudas para cada espécie de acordo com o planejamento, esta informação será repassada ao órgão de fiscalização da Unidade da Federação (MAPA), onde a fonte de sementes esteja instalada, até 30 (trinta) de março do ano corrente.

Segundo determinado pelo RENASEM, as mudas, durante o processo de produção, devem estar identificadas, individualmente ou em lotes, com no mínimo o nome científico e nome comum da espécie e, quando for o caso, de cultivar, obedecida a denominação constante no RNC.

Quando se tratar de produção de sementes ou de mudas das espécies florestais para uso próprio (ser utilizadas apenas em propriedade de sua posse, sendo proibida a comercialização do material produzido), não é necessário o registro no RENASEM, porém deve ser declarada, anualmente, ao MAPA a produção de sementes ou de mudas destinadas para uso próprio. 